\title{
WHY DO GOOD HUNTERS HAVE HIGHER REPRODUCTIVE SUCCESS?
}

\author{
Eric Alden Smith \\ University of Washington
}

\begin{abstract}
Anecdotal evidence from many hunter-gatherer societies suggests that successful hunters experience higher prestige and greater reproductive success. Detailed quantitative data on these patterns are now available for five widely dispersed cases (Ache, Hadza, !Kung, Lamalera, and Meriam) and indicate that better hunters exhibit higher age-corrected reproductive success than other men in their social group. Leading explanations to account for this pattern are: (1) direct provisioning of hunters' wives and offspring, (2) dyadic reciprocity, (3) indirect reciprocity, (4) costly signaling, and (5) phenotypic correlation. I examine the qualitative and quantitative evidence bearing on these explanations and conclude that although none can be definitively rejected, extensive and apparently unconditional sharing of large game somewhat weakens the first three explanations. The costly signaling explanation has support in some cases, although the exact nature of the benefits gained from mating or allying with or deferring to better hunters needs further study.
\end{abstract}

KEY WORDS: Food sharing; Hunter-gatherers; Reciprocity; Signaling

A growing body of evidence suggests that men who are more successful in hunting endeavors experience higher prestige and greater reproductive success. Anecdotal data indicating a link between hunting success and prestige has been reported for a wide variety of hunter-gatherer societies and will be reviewed below. A link to demographic outcomes such as fertility, number of mates, offspring survivorship, and lifetime reproductive success has been reported less often, but quantitative data bearing on such links are now available for at least five widely dispersed cases: Ache (South America), Hadza (East Africa), !Kung (southern Africa), Lamalera (Indonesia), and Meriam (Melanesia). Such a link appears rather surprising

Received January 7, 2004; accepted April 9, 2004; revised version received May 10, 2004.

Address all correspondence to Eric Alden Smith, Department of Anthropology, University of Washington, Seattle,WA98195-3100 USA.Email: easmith@u.washington.edu

Copyright $(C) 2004$ by Aldine Transaction, New Jersey

Human Nature, Vol. 15, No. 4, pp. 343-364.

$1045-6767 / 98 / \$ 6.00+.15$ 
in light of the abundant ethnographic evidence that most ethnographically known hunter-gatherer societies have egalitarian sociopolitical organization, marked absence of economic inequality, extensive meat-sharing practices (which greatly reduce the nutritional consequences of differences in hunting ability), and various "leveling mechanisms" to discourage social and economic status differentiation (e.g., Kelly 1995). Despite these features, gains in reproductive success (number of surviving offspring) on the order of $50-100 \%$ appear to accrue to successful hunters, as summarized below.

The existence of a robust relationship between economic production (e.g., hunting success) and a major component of differential fitness (reproductive success) is significant well beyond the realm of huntergatherer societies. First, the theory of natural selection places heritable individual differences that affect differential reproduction at the center of evolutionary dynamics. Although we do not know the extent of heritability in hunting success, it is highly likely that both genetic and cultural transmission shapes differential success in this domain. Second, despite the debate on the relevance of reproductive success measures in evaluating hypotheses about adaptive design (Symons 1989; Smith 1998; Smith et al. 2001), most evolutionary social scientists would agree that a consistent correlation between reproductive success and hunting success is informative about the course of human evolution. But this correlation does not tell us much about the specific forces producing this relationship; that is why examination of leading hypotheses, and their relative explanatory power, is required.

The leading hypotheses that have been suggested to account for the correlation between hunting success and reproductive success are: (1) direct provisioning of hunters' wives and offspring; (2) dyadic reciprocity (e.g., exchanging meat for alliances or sexual access); (3) indirect reciprocity (e.g., granting privileges to good hunters or their offspring in order to encourage them to continue providing collective benefits); (4) costly signaling (where hunting success signals underlying qualities preferred in mates or allies); and (5) phenotypic correlation (where hunting success and reproductive success are both effects of some third variable, such as robust health). These hypotheses have quite different implications for the selective forces and resulting adaptive design that may have shaped productive and reproductive striving in hunter-gatherer societies, as will be discussed below.

The remainder of the paper is organized as follows. First, I briefly summarize the evidence that hunting success is correlated with enhanced prestige and higher reproductive success. I then review the qualitative 
and quantitative evidence from a variety of foraging societies bearing on the five different hypotheses just outlined and draw some tentative conclusions about the explanatory power of these hypotheses. I conclude with a discussion of the implications these findings might have for understanding aspects of human behavioral evolution, forager demography, and status differentiation in small-scale societies, as well as the prospects for further research to address unresolved issues.

\section{THE EVIDENCE}

Before considering alternative explanations for the association between hunting success and social and reproductive benefits, it is worth reviewing the empirical evidence for such a pattern. I will first consider qualitative evidence derived from a broad range of foraging societies and then turn to a review of the quantitative evidence available from a small number of them.

\section{Qualitative Evidence}

Status differentials vary in importance across hunter-gatherer societies, with some societies characterized by ranked status differences based on inherited titles, privileges, and property (e.g., Bean 1976; Ruyle 1973). Here I am concerned with more egalitarian groups, where status is primarily achieved. In a survey of 25 such societies, Wiessner (1996) judged that good hunters gain higher status in $15(60 \%)$, and sharing generously is highly valued in all. Many ethnographic accounts discuss the ways in which hunting success is both socially downplayed (by discouraging boasting and the like) and yet socially rewarded. For example, a study of aboriginal foragers in Arnhem Land concludes that despite an emphasis on equal access to the catch, good hunters "will always acquire prestige. People are acutely aware of who the successful hunters are" (Altman and Peterson 1988:80). Similar statements are common in the ethnographic literature on hunter-gatherers, though of course without detailed evidence to back them they are vulnerable to skepticism and anecdotal counterexample.

\section{Quantitative Evidence}

The primary quantitative evidence reported here comes from five contemporary foraging populations: Ache, Hadza, !Kung, Lamalera, and Meriam. To my knowledge, these are the only cases for which published 
quantitative evidence is available. I will briefly review each case, in alphabetical order.

The Ache are recently settled forest-dwelling people whose pre-settlement nomadic foraging demography and ecology have been studied in detail by Hill, Hurtado, and colleagues (Hill and Hurtado 1996). Among the Ache, hunting skill (as ranked by interviews with Ache) was positively correlated with fertility (logistic multiple regression controlling for age, odds ratio $=15.155$, partial $p=0.001, n=176$ men, 538 births), as well as lower offspring mortality for ages $5-9$ (odds ratio $=8.309, p=$ 0.003, controlling for age) but not other ages (Hill and Hurtado 1996:301, 316 , Tables 10.2 and 10.6). The results are similar when measured individual hunting return rates are used rather than informant rankings.

The Hadza inhabit an East African savannah fairly rich in both large game and plant foods, and they have been studied for a number of years by Blurton Jones, Hawkes, Marlowe, and O'Connell (e.g., Blurton Jones et al. 1992; Hawkes et al. 2001a). Marlowe has documented that hunting reputation (as ranked by Hadza informants) is positively correlated with male fertility $(r=0.357, p=0.022$, partial correlation controlling for age, $n=39)$ and marriage to younger wives $(r=0.376, p=0.01, n=46)$, but not with number of wives $(r=-0.016, p=0.91$, controlling for age) (Marlowe 1999:401, 2000:33). Using a somewhat different data set and methods, Hawkes and colleagues (2001b) also show that better hunters tend to have younger wives and provide evidence that these men also have harder-working (more economically productive) wives. This evidence of assortative mating is bolstered by reports that women cite "good hunter" as the single most valued trait in a potential husband (Marlowe 2003:225).

The !Kung or Ju/'hoansi inhabit parts of the Kalahari Desert in Botswana and adjacent portions of Namibia. Although !Kung ecology and demography has been extensively researched by Lee (1979), Howell (1979), and Blurton Jones (1986), among others, the only available data on the relation between hunting success and RS were collected and analyzed by Wiessner (2002). For a small but richly documented sample of 26 !Kung men, all age 55 or greater (and hence likely to have completed reproduction), better hunters $(n=14)$ had more than $50 \%$ higher fertility than poorer hunters $(n=12, t$-test $p=0.18)$, and nearly twice as many surviving offspring (3.8 vs. 2.0, $t$-test $p=0.08$ ), but did not have more wives, nor younger wives. The better hunters' current wives averaged $65 \%$ more surviving offspring, though this difference did not approach statistical significance ( $t$-test $p=0.25, n=18$ ).

The residents of Lamalera on the Indonesian island of Lembata specialize in hunting sperm whales and giant rays, from traditional wooden 
boats crewed by 8-14 men (Alvard and Nolin 2002). Each boat crew includes a harpooner, a helmsman, and a harpooner's assistant, as well as the other crew members. Men who regularly engage in whaling ("hunters") have significantly more surviving offspring than the average male, after controlling for age (Alvard and Gillespie in press). While the RS differential of whale hunters as a whole is modest (ANCOVA controlling for age, $F=9.60, p=0.002, n=364$ ), those who specialize as harpooners achieve an RS twice as great as non-hunters (4.7 vs. 2.3 surviving offspring; ANCOVA controlling for age, $F=24.06, p<0.001, n=20$ and 133). Harpooners also marry significantly earlier and start reproducing at an earlier age (Kaplan-Meier hazard analyses); none of these differentials applies to helmsmen or other specialized roles associated with whaling (e.g., carpenter, sailmaker). As harpooners' rate of production of surviving offspring is no higher than that of other men, this early start appears to account for their greater RS. Neither harpooners nor other hunters are more likely to marry significantly younger women than other men, so this does not appear to be the source of differential fertility. While harpooners do receive a larger share of the catch than other hunters, multivariate analyses indicate that hunting effort and relative share of the catch do not predict RS whereas harpooner status does, even when controlling for these other variables (Alvard and Gillespie in press).

The Meriam are a Melanesian people of eastern Torres Strait, Australia, with a marine foraging and (until recently) horticultural economy. Other than the very occasional dugong, the only large game taken by Meriam are marine turtles (green turtles, Chelonia mydas, harvested live weight $100-150 \mathrm{~kg}$; average edible weight, $50.1 \mathrm{~kg}$ ). Many turtles are collected on beaches during the nesting season, by women and children as well as men. During the non-nesting season, turtles must be hunted offshore, which requires considerable skill and knowledge even with motorized boats. Currently fewer than half of Meriam men ever engage in turtle hunting; hence, our analysis compares hunters to non-hunters (Bliege Bird et al. 2001; Smith et al. 2003). The reproductive success (number of surviving offspring of all ages) of Meriam turtle hunters is about 1.7 times higher than that of non-hunters (ANCOVA controlling for age, $F=$ 7.543, $p=0.007, n=98 \mathrm{men}$ ), and extrapolating observed age-specific rates to age 50 would result in about 2.4 more surviving offspring for hunters than for non-hunters. Compared to non-hunters, Meriam hunters display a lower mean age at birth of first child (Kaplan-Meier hazard analysis, $p=0.004, n=114 \mathrm{men}$ ), and about $65 \%$ more mates (women with whom they have borne offspring; ANCOVA controlling for age, $F=$ 10.096, $p=0.002, n=144$ men). Neither hunters' mates nor their current 
coresidential partners are younger than those of non-hunters, but Meriam nominated as "hard-working women" in interviews with a broad sample of Meriam adults of both sexes are significantly more likely to be hunters' mates (unpaired $t$-test $p=0.045,165 \mathrm{df}$ ). Analyses reveal that those hunters who serve as hunt leaders (crew captains) exhibit higher cumulative RS and higher mean number of mates, as well as a shorter waiting time to the birth of the first offspring, relative to other hunters (Smith et al. 2003).

\section{EVALUATING ALTERNATIVE EXPLANATIONS}

\section{Direct Provisioning}

Perhaps the simplest explanation of the correlation between hunting success and RS is that better hunters have better-fed wives and children, thereby enhancing spousal fertility and/or offspring survivorship. I will refer to this as the "direct provisioning" hypothesis. Testing this hypothesis is not as straightforward as it may appear. Although evidence that wives of better hunters have higher fertility, or their offspring have lower mortality, is consistent with the direct provisioning hypothesis, it may also be consistent with alternatives. For example, assortative mating may increase the probability that better hunters will obtain higher-fertility wives (because of their genetic or phenotypic qualities), irrespective of their husband's provisioning. Similarly, higher survivorship of offspring may be due to inheritance of genetic quality, better treatment by others in the social group (Kaplan and Hill 1985a), or similar "indirect" routes.

A better test of the direct provisioning hypothesis would be to see if rate of food delivery by hunters to their own wives and offspring is $(a)$ higher among better hunters and $(b)$ correlated with variation in offspring survivorship and/or spousal fertility. Unfortunately, such data have not been published for any of the hunter-gatherer societies for which we have data on variation in male RS as a function of hunting success. The Ache data indicate that in the current settled and farming-dependent reservation context, the portion kept by the acquirer's family is higher than the average portion received by other families (Gurven et al. 2002), and a measure of household socioeconomic status is weakly associated with child survivorship (Hill and Hurtado 1996). In contrast, data from multi-day hunting trips, which more closely match the pre-agricultural lifeways of the Ache, indicate that there is no kin bias in sharing game (Kaplan and Hill 1985b), and that if anything a smaller portion of a hunter's catch goes to his own household than to others. 
Although the Ache non-settlement pattern of kinship-neutral sharing appears to be extreme, there is ample evidence from a variety of egalitarian foraging societies for extensive sharing of game between households (Kelly 1995:164ff; Gurven 2005). Such extensive sharing will certainly reduce the between-household variation in "take-home" catch that would otherwise be associated with differences in hunting success. More direct quantitative tests are certainly needed, but differences in direct provisioning would have to be extreme to account for the higher RS of better hunters of the magnitude observed among the !Kung (1.9 times higher) or the Meriam (1.7 times higher). It is certainly possible, however, that provisioning could account for some portion of observed variation in male RS in these and other cases.

Among the Hadza, the fact that the wives and children of better hunters display greater seasonal weight gains (Hawkes 1993b) may be associated with variation in women's foraging returns rather than those of their husbands (Hawkes et al. 1997). However, Marlowe (2003) has recently shown that Hadza women with very young children $(<3$ years old), and especially those with infants $(<1$ year old), have reduced foraging productivity, both in average daily harvest and in hourly return rates while foraging. In contrast, their husbands exhibit increased harvests and (to a lesser extent) increased return rates, thus compensating for the lower productivity of the women with young offspring. In fact, while most Hadza women bring in slightly more foraged calories than their husbands, women with infants bring in an average of $2,140 \mathrm{kcal} /$ day less than their husbands (Marlowe 2003:222). Interestingly, the greater harvest of men with young offspring is entirely non-meat resources, particularly honey, which are not as widely shared as large game.

Meriam men (along with women and children) are often active in collecting turtles during the nesting season. Since more turtles are harvested this way than by hunting, those men who collect turtles but do not hunt them should be provisioning their own households at as high or higher a rate than hunters, particularly given that hunted turtles are shared much more widely than collected turtles, often being donated entirely to communal feasts (Bliege Bird et al. 2001). Yet nonhunter-collectors do not show statistically significant elevation of RS relative to other men, whereas hunter-collectors do (Smith et al. 2003). In addition, Meriam men who are noted as exceptional fishermen (a more reliable form of household provisioning than turtle hunting) do not have higher average age-specific and cumulative RS than other men; even more tellingly, if we divide these exceptional fishermen into those who are also turtle hunters and those who are not, the former have much higher cumulative RS (4.9 off- 
spring, similar to turtle hunters as a whole) than the latter (1.1 offspring), a difference that is statistically significant despite the small sample size ( $n$ $=13$ ) (Smith et al. 2003).

\section{Dyadic Reciprocity}

A second explanation for the hunting success-RS correlation is that better hunters bestow their greater harvests on particular other individuals in exchange for RS-enhancing social benefits. The most commonly proposed form for such exchange posits that meat is exchanged for mating access (e.g., Kaplan and Hill 1985a), but a variant proposes that the hunter's payback comes through political alliances (Sugiyama and Chacon 2000; Patton 2004, 2005).

Although it is difficult to study sexual behavior, demographic data can reveal reproductive outcomes of sexual partnerships, and these outcomes are after all the key ones for explaining variation in RS. With regard to meat-for-mating reciprocity, the quantitative evidence is quite mixed. Better hunters have a higher mean number of mates (women with whom they have had offspring) in at least two cases (Ache and Meriam) but apparently not in two others (Hadza and !Kung). Even in those cases where better hunters do have more mates, this may be for reasons other than dyadic reciprocity (as discussed below under "costly signaling").

In addition, theory (Dugatkin 1997) clearly indicates that cooperation of the sort envisioned in the meat-for-mating hypothesis requires safeguards against cheating in order to be stable; at the least, the reciprocity must conditional (I cooperate with you only if you cooperate with me). The extensive sharing of large game observed in many egalitarian foraging societies appears to weaken this hypothesis, although direct evidence on conditionality is hard to come by. If game (or at least large game) is widely shared, a hunter cannot conditionally withhold it from those who do not offer sexual or other favors (Hawkes 1993a). Gurven's (2005) review of the quantitative data on hunter-gatherer sharing shows that the correlation of amount of meat acquirer $\mathrm{A}$ gives to recipient $\mathrm{B}$ with the amount $\mathrm{B}$ gives to $\mathrm{A}$ (averaged over all acquirers and recipients, and over some specified time period) varies from -0.16 to 0.46 , with an average of 0.2 ( $n=6$ societies). This means that most $(80 \%)$ of the meat given to other households does not get reciprocated; however, these data do not speak directly to the question of conditional reciprocity involving nonmeat favors returned.

What about dyadic reciprocity involving alliance support exchanged for meat? All the questions raised in the preceding paragraph regarding 
the meat-for-mating hypothesis would appear to apply to it as well, assuming such support is costly to the hunter's allies. As far as I know, there is no direct evidence bearing on the alliance version of the dyadic reciprocity explanation, though it has been argued to account for patterns of hunting and alliance behavior observed in a population of chimpanzees (Mitani and Watts 2001). Bliege Bird et al. (2001) show that Meriam do not preferentially name turtle hunters as political allies, though observational data on alliance behavior is lacking. Sugiyama and Chacon (2000) and Gurven et al. (2000a) document that better hunters receive preferential treatment when incapacitated, but this is not direct evidence of reciprocal exchange of meat for aid and is consistent with alternative explanations, such as costly signaling (Gurven et al. 2000a), as discussed further below.

\section{Indirect Reciprocity}

If successful hunters share their catch widely, their hunting may be of benefit to most or all members of their local community. Perhaps then they are rewarded through indirect reciprocity rather than dyadic exchanges. Indirect reciprocity refers to cases where those who develop a reputation for bestowing benefits are themselves preferentially chosen by third parties to be the recipients of benefits (Alexander 1987; Boyd and Richerson 1989). The logic of the indirect reciprocity explanation is not usually spelled out in as much detail as is that of dyadic reciprocity, but the following statement is exemplary:

Foragers do better to choose neighbors who provide collective goods. If there are advantages to being preferred as a neighbor, individuals can gain them by trading off the consumption advantages from targeting private goods and supplying collective goods instead. Advantages may include deference in decisions about travel, support in disputes (or at least reluctance on the part of others to side against them), and enhanced mating opportunities (Hawkes 1993a:349).

Note that the reciprocity proposed here is $(a)$ indirect (comes from many members of the social group, not just those who trade benefits dyadically with good hunters), (b) delayed (aimed at ensuring the future presence and effort of successful hunters), and (c) nutritionally motivated (by the food that hunters bestow upon group members).

Proposed forms for such indirect reciprocity besides those listed in the Hawkes quotation include better treatment of good hunters' offspring (Kaplan and Hill 1985a), toleration of cuckoldry (Hawkes 1990), and 
most broadly what Hawkes (1993a) has termed "social attention." Regardless of the proposed currency, it appears that no one has gathered sufficient data to test the indirect reciprocity explanation formally. This means the evaluation of this explanation must be very preliminary and based primarily upon theoretical issues rather than empirical data. The most important of these issues is that, as described above, this form of benefit exchange entails a serious collective-action problem (Smith 1993). That is, the explanation depends upon providing incentives (deference, etc.) to good hunters to encourage them to hunt and share their catch. But given generalized sharing of the catch, such incentives are a collective good (i.e., they are available to all members of the social group, not just those who provide the incentives). Although this objection would lose its power if these incentives could be provided at no cost to the providers, it is not clear how cost-free acts could in fact result in significant benefits to recipients (hunters). Accordingly, if those who fail to provide incentives to good hunters can still obtain the benefit (shares of the catch), they will experience a higher net gain than those who do provide these incentives, and the motivation to provide such benefits to better hunters is fatally undermined.

But suppose better hunters are willing to move to another group if they are not granted sufficient rewards for their productive beneficence. Even if this is the case, for any group members to take actions that are personally costly in order to persuade good hunters not to change camps raises precisely the same kind of collective action problem just discussed. Having a productive hunter in my camp, given that his harvest is shared unconditionally with all camp members (or all camp members who happen to be around when the game is butchered), is a public good. I will gain access to that public good whether or not I am nice to him, unless he leaves, in which case those people who were nice to him will also lose such access. If not enough people reward good hunters with social benefits, they may leave, but this does not provide an incentive to any one recipient to do so (following the logic of the n-player Prisoner's Dilemma). Whether the good hunter leaves or stays, free-riders will still come out ahead of their peers. A solution to this collective-action problem may be possible within the indirect reciprocity framework, if those who provide collective goods are preferentially chosen as partners in private exchanges that benefit both parties (Milinksi et al. 2002; Mohtashemi and Mui 2003; Panchanathan and Boyd 2004). However, this requires a system of conditional reciprocity separate from, but linked to, provisioning of collective goods. It is precisely this requirement that is absent if recipients of the hunter's largesse reciprocate with social benefits simply to ensure further largesse. 


\section{Costly Signaling}

Costly signaling theory is concerned with explaining the evolutionary stability ("honesty") of communication, but it has recently been extended to account for various forms of cooperation and public goods provisioning (Boone 1998; Gintis et al. 2001; Neiman 1998; Smith and Bliege Bird 2000; Zahavi 1995). In the present context, we can use this theory to predict that hunting success serves as an honest signal of the hunter's underlying phenotypic qualities (such as vigor, intelligence, economic productivity, and/or fighting ability) or intentions (to cooperate, share generously, etc.), attributes that may be valued by prospective mates and allies, or allow competitors to assess the hunter's competitive abilities and to avoid competing with him if they judge him competitively superior (Smith and Bliege Bird 2000). In order for hunting success to be an honest signal of one or more such qualities, signaling intensity (successfully hunting and sharing game) must be quality-dependent, meaning that individuals of higher quality pay lower marginal signaling costs (e.g., they are more efficient hunters) or gain higher marginal signaling benefits (e.g., their catch is more highly valued than that harvested by other foragers). This condition seems likely to be met for at least some kinds of hunting, particularly those forms that are skill-based (e.g., hunting of large, rare, evasive, or dangerous prey), while being less likely to apply to gathering of sessile animals (e.g., shellfish) or plant resources (Smith and Bliege Bird 2000).

The costly signaling explanation of hunting effort and its social (and reproductive) rewards share some features with the "show-off" model (Hawkes 1993a) but differ in certain key respects (Smith and Bliege Bird 2000; Hawkes and Bliege Bird 2002). In particular, the signaling explanation avoids the collective action problem raised by indirect reciprocity, proposing that when better hunters are preferred as mates or allies, or deferred to in male-male competition, this is simply the responder's best move, rather than being a form of reciprocity or payback for sharing food (Gintis et al. 2001). Thus, if hunting success reliably signals qualities that make the hunter a superior mate or ally or a more formidable competitor, then observers should compete to engage in such mutually beneficial interactions with the hunter, and there should be no temptation to free-ride at the expense of others.

In this framework, any material gains through eating shares of the hunter's catch are an additional non-signaling benefit and not the final goal of the signaling effort. This has led to the question of why hunters would signal by contributing goods to others (capturing and sharing large 
game) rather than behaving more selfishly (simply provisioning their own close kin). One answer is that such widespread sharing may be a means by which hunters attract a wider audience to observe their signaling (Smith and Bliege Bird 2000). Another is that successfully providing a collective benefit may reliably signal ability to provide private benefits to mates or allies (Gintis et al. 2001) - a possible correlation between signaling and provisioning that I will return to below. A third possibility is that providing benefits to others may signal commitment to an ongoing relationship (Zahavi 1995; Smith and Bliege Bird 2005). This last possibility suggests that signaling theory can account at least in part for why observers who don't receive shares from a successful hunt might express displeasure with the hunter, since failure to be given shares may signal weakening or termination of a valued relationship.

To date, the costly signaling explanation for hunting and sharing of game, and for the social and reproductive gains experienced by successful hunters, has been examined in detail only among the Meriam (Bliege Bird et al. 2001; Smith et al. 2003), though some elements of the explanation have been examined among the Ache (Gurven et al. 2000a, 2002; Wood and Hill 2000), Lamalerans (Alvard and Gillespie in press), and Micronesian fishermen on Ifaluk (Sosis 2000). The empirical results appear consistent with this explanation in each case. On the other hand, Wiessner (2002) argues that among the !Kung, hunting efforts by older men (in their forties and fifties) are unlikely to be motivated by signaling to attract mates; given the very low levels of polygyny and extramarital reproduction observed in this population, her argument is convincing. She proposes instead that better hunters are able to hold together a group of close kin over the long haul, and in turn this group can retain control of important territorial resources. It's not clear that Wiessner's hypothesis (or some variant of it) would apply in cases like Ache or Hadza, where territorial claims are weak or absent and membership in residential groups is extremely fluid (at least prior to externally imposed settlement schemes). It also seems unlikely to apply to Meriam turtle hunters or Lamaleran whalers, where the catch is widely shared and the settlement contains large numbers of non-relatives.

\section{Phenotypic Correlation}

The final explanation to be considered here belongs to the general class termed "phenotypic correlation" in behavioral ecology (e.g., Lessells 1991). Phenotypic correlation is a frequent complication in non-experimental data sets. In the present case, it would apply if the association between 
hunting success and RS were due to some correlated independent variable rather than to a direct causal relationship between the hunting success and RS. For example, we might suppose that hunting success is a byproduct of greater disease resistance, strength, intelligence, etc., and that these factors also result in higher RS regardless of an individual's hunting behavior.

Although such an explanation for the observed correlation is certainly plausible, it is not easy to test without experiments - and it is difficult to imagine appropriate experiments that are both feasible and ethical. In addition, the phenotypic correlation explanation is not clearly distinct from at least some versions of costly signaling (e.g., a correlation between vigor or intelligence and hunting success that also leads to higher $\mathrm{RS}$ is quite congruent with hunting as an honest signal). The closest we have to an empirical test for the present question is rather indirect: Smith et al. (2003) compared Meriam turtle hunters to their age-matched nonhunting brothers (full or half sibs) and found that both observed RS and computed age-specific RS of the non-hunters was less than half that of the hunters, and in fact closely tracked RS in the rest of the non-hunting Meriam male sample (Figure 1). Although this test does not strictly eliminate the hypothesis that there are phenotypic differences between hunters and other men that result in the RS differentials independently of hunting success, by partially controlling for genetic and familial endowment it does make that hypothesis less plausible.

\section{DISCUSSION AND CONCLUSIONS}

The main conclusions of this paper can be summarized as follows. First, there is robust evidence for a correlation between the hunting success and reproductive success of individual men within the several societies where relevant data are available. Second, the proximate causes of this correlation vary somewhat between societies, with better hunters sometimes (but not always) having more mates, higher-quality mates, earlier reproduction, and higher offspring survival (see Table 1). We are not aware of any direct evidence for (or against) genetic differences underlying variation in RS; all of the explanations reviewed here are consistent with such variation being purely or largely phenotypic. Third, of the several alternative accounts for the deeper mechanisms that might underlie the hunting-RS correlations (and its proximate determinants), those involving direct nutritional inputs, dyadic exchange, or indirect reciprocity are challenged by the extensive and sometimes unconditional sharing of large game in these and other foraging societies. However, the currently available 
Figure 1. Cumulative age-specific RS of Meriam turtle hunters and their age-matched non-hunting brothers.

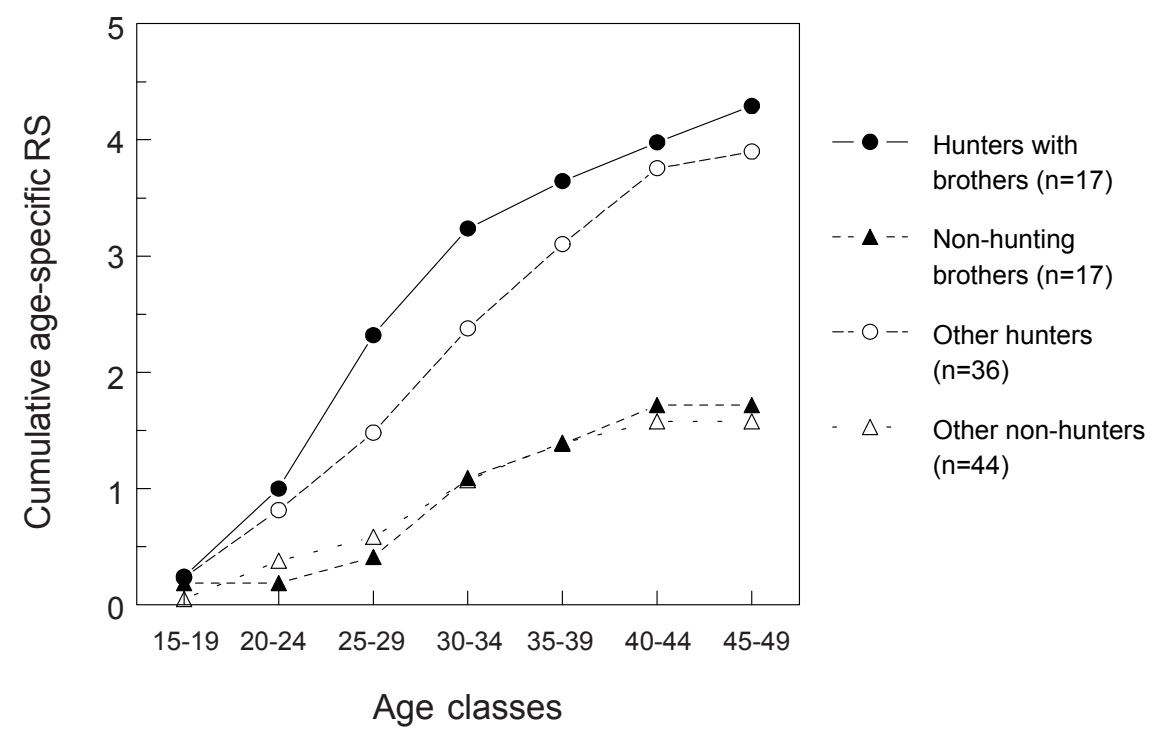

data are not sufficient to rule out any of the candidate explanations. The costly signaling explanation appears to accord with the evidence from Meriam, Lamalerans, and perhaps Ache, but the exact nature of the benefits gained from mating or allying with better hunters is not well established and needs further research.

It seems likely that explaining why better hunters have higher RS will require a synthesis of several hypotheses (such as the ones reviewed in this paper), and that the exact mix of explanatory factors varies between societies. Empirically, it seems pretty clear that success in big game hunting leads to one or more of the following outcomes: (1) increased reproductive success (found in all cases where quantitative evidence is available); (2) enhanced social status (qualitatively found in most or all); and (3) increased economic exchange opportunities (found in some cases). The enhanced RS of better hunters must be due to some combination of direct female choice and/or enhanced social status or power, resulting in better hunters having more and/or higher-quality mates.

If direct female choice is involved, then we expect that females must gain something from this mating preference. This might involve provisioning benefits (if better hunters are also better providers, at least during 
Table 1. Summary of Quantitative Evidence on Reproductive Correlates of Hunting Success in Five Societies

\begin{tabular}{llcccc}
\hline Society & $\begin{array}{c}\text { Higher } \\
\text { fertility }\end{array}$ & $\begin{array}{c}\text { More } \\
\text { surviving } \\
\text { offspring }\end{array}$ & $\begin{array}{c}\text { Younger age } \\
\text { at first child }\end{array}$ & More mates & $\begin{array}{c}\text { Younger } \\
\text { mates }\end{array}$ \\
\hline Ache & Yes $^{\mathrm{a}}$ & Yes $^{\mathrm{b}}$ & $?$ & Yes & $?$ \\
Hadza & Yes $^{\mathrm{a}}$ & $?$ & $?$ & No & Yes $^{\mathrm{a}}$ \\
!Kung & $\mathrm{Yes}^{\mathrm{a}}$ & $\mathrm{Yes}^{\mathrm{a}}$ & $?$ & No & $?$ \\
Lamalera & Yes $^{\mathrm{a}}$ & Yes $^{\mathrm{a}}$ & Yes & $?$ & No \\
Meriam & Yes $^{\mathrm{a}}$ & Yes $^{\mathrm{a}}$ & Yes & Yes $^{\mathrm{a}}$ & Yes \\
\hline
\end{tabular}

${ }^{a}$ Controlling for age

${ }^{\text {b }}$ Offspring survivorship rate, for ages 5-9 only

critical periods such as late pregnancy and nursing), genetic benefits that can be inherited by offspring (if hunting success is a reliable signal of genetically mediated health, vigor, or cognitive ability), or other social benefits, such as enhanced protection (if hunting success is a signal of fighting ability). As noted above, the problem with the provisioning route to enhanced RS is that the fruits of hunting success are usually shared beyond the hunter's household. However, if hunting success serves as a reliable signal of broader foraging ability, and hence of overall provisioning ability, then this problem might be solved. Recent evidence from the Hadza (Marlowe 2003) noted above indicates that this might be the case, as Hadza men increase their net provisioning dramatically when their wives are caring for young children, and this provisioning focuses on small game and honey, thereby avoiding widespread sharing demands. Thus, men might signal their foraging abilities widely through success in hunting and extensive sharing, thereby obtaining increased social status, allies, mates, or other social benefits, while the wives of these men can count on higher provisioning during periods of critical need. Indeed, Marlowe (2003:224) reports that among the Hadza, reputation as a good hunter is more even more highly correlated with total foraging returns than with returns from hunting (perhaps because good hunters have more offspring, and thus engage in provisioning more intensively). Furthermore, if at least part of the year is spent dispersed in very small groups, which is the case in many foraging societies, a large proportion of hunting returns will go to direct provisioning (Ray Hames, personal communication 2003).

If higher RS of good hunters is due to enhanced social status, then we expect that those granting this status must gain something thereby. They might be obtaining superior economic or political alliances (Gintis et al. 
2001; Wiessner 2002), avoiding costly conflict with better fighters (Smith and Bliege Bird 2000), gaining access to valuable knowledge (Henrich and Gil-White 2001), or retaining high producers in their group (Hawkes 1993a). As discussed above, the last of these raises a collective-action problem (but see Wiessner 2002 for a possible solution). In any case, the pervasive qualitative evidence that better hunters have higher social status needs to be bolstered by more rigorous empirical and analytical work so that we can better understand this important phenomenon.

Several broader implications of the findings reviewed in this study deserve mention. First, the correlation between socially valued activities (e.g., hunting success) and RS summarized herein is not ethnographically unusual. In numerous pre-industrial societies, including a variety of horticultural, agrarian, and pastoralist populations, researchers have found that social status (whether economically defined or not) correlates positively with RS, at least in males (e.g., Barkow 1977; Borgerhoff Mulder 1988; Cronk 1991; Flinn 1986; Irons 1979; Low and Clarke 1991; Turke and Betzig 1985; Voland 1990). Some evidence even suggests that this correlation may hold in industrialized societies (Hughes 1986; Low 2000), though contrary evidence does exist (Kaplan et al. 1995; Borgerhoff Mulder 1998).

Second, the social mediation of RS is pervasive and goes well beyond the "leveling" mechanisms emphasized by some students of huntergatherer societies. Although the five cases reviewed range from the extremely informal and almost anarchic Hadza to the Meriam and Lamalerans with their patrilineal clans and relatively strong age-gender hierarchies, all can be classified as egalitarian relative to large-scale agricultural and industrial societies. Furthermore, economic inequality within each of these societies is minimal, and we could expect extensive game sharing to reduce or eliminate any impact of hunting ability on reproductive differentials (Wilson 1998; Bowles et al. 2003). But in fact (as summarized above) these differentials appear to be substantial. Although the available evidence cannot rule out a direct nutritional basis for the observed RS differentials, it strongly suggests these are not enough to fully account for them. And other evidence indicates that social interactions - mating success, earlier onset of reproduction, preferential treatment, and the likeplay a central, causal role. This implies that even in societies (such as these) where sociopolitical inequality is informal, and economic inequality minimal or absent, differential RS can be quite pronounced.

Third, the patterns summarized above have implications for our understanding of the adaptive significance of food sharing, and the social context of economic behavior. Models of conditional reciprocity (e.g., Trivers 1971; Axelrod and Hamilton 1981) have dominated economic and evolu- 
tionary accounts of resource sharing. Although there is evidence for the importance of reciprocity in some egalitarian food-sharing systems (e.g., Hames 2000; Gurven et al. 2000b, 2001), there is also evidence that is inconsistent with such a framework (e.g., Kaplan and Hill 1985b; Hawkes 1993a; Hawkes et al. 2001a; Bliege Bird et al. 2002). In parallel with developments in animal behavior (e.g., Clements and Stephens 1995; Dugatkin 1997) and evolutionary/economic theory (e.g., Boyd and Richerson 1988; Gintis et al. 2001; Sigmund et al. 2002), students of human ecological adaptation are rethinking the centrality of reciprocity in socioeconomic relations, and moving towards a more pluralistic view (Winterhalder 1996). The findings summarized here can only add to this trend.

For comments on earlier drafts, I thank Monique Borgerhoff Mulder, Mike Gurven, Ray Hames, Kristen Hawkes, Kim Hill, Robert Kelly, Frank Marlowe, John Patton, and Polly Wiessner. Rebecca Bliege Bird and Douglas W. Bird invited me to collaborate in the Meriam research and (along with Del Passi of Mer) collected the data on Meriam demography. Geoff Kushnick and Matt Wimmer ably assisted with coding and statistical analysis of these data. I thank the Meriam people, and particularly the Passi family, for their generosity, and the National Science Foundation for funding the research on Mer (grants to RBB, DWB, and EAS).

Eric Alden Smith (PhD 1980, Cornell University) is a professor of anthropology at the University of Washington, Seattle. His research interests include the links between production and reproduction, the ecology and evolution of collective action, and politics in small-scale societies. He has conducted fieldwork among Inuit on Hudson Bay, Meriam in Torres Strait, and Mardu Aborigines in the Australian Western Desert.

\section{NOTES}

1. Alvard and Gillespie (in press) classified Lamaleran males $>15$ years of age as "hunters" if their hunting frequency fell above the tenth percentile of the adult male population; this amounted to 231 individuals, $63 \%$ of all Lamelaran men.

2. Although the !Kung data refer to "wives" rather than mates per se (Wiessner 2002), the rate of extramarital reproduction appears to be very low (ibid.). Alvard and Gillespie (in press) do not provide information on variation in number of mates on Lamalera.

\section{REFERENCES}

Alexander, Richard D.

1987 The Biology of Moral Systems. Hawthorne, New York: Aldine de Gruyter. Altman, Jon, and Nicolas Peterson

1988 Rights to Game and Rights to Cash among Contemporary Australian Huntergatherers. In Hunters and Gatherers: History, Evolution and Social Change, T. Ingold, D. Riches, and J. Woodburn, eds. Pp. 75-94. Oxford: Berg. Alvard, Michael S., and Allan Gillespie

in press Good Lamalera Whale Hunters Accrue Reproductive Benefits. Research in Economic Anthropology 24. 
Alvard, Michael S., and David Nolin

2002 Rousseau's Whale Hunt? Coordination among Big-game Hunters. Current Anthropology 43:533-559.

Axelrod, Robert, and William D. Hamilton

1981 The Evolution of Cooperation. Science 211:1390-1396.

Barkow, Jerome

1977 Conformity to Ethos and Reproductive Success in Two Hausa Communities. Ethos 5:409-425.

Bean, Lowell J.

1976 Social Organization in Native California. In Native Californians: A Theo-

retical Retrospective, L. J. Bean and T. C. Blackburn, eds. Pp. 99-123. Ramona, California: Ballena Press.

Bliege Bird, Rebecca L., Douglas W. Bird, Eric A. Smith, and Geoffrey Kushnick 2002 Risk and Reciprocity in Meriam Food Sharing. Evolution and Human Behavior 23:297-321.

Bliege Bird, Rebecca L., Eric A. Smith, and Douglas W. Bird 2001 The Hunting Handicap: Costly Signaling in Human Foraging Strategies. Behavioral Ecology and Sociobiology 50:9-19.

Blurton Jones, Nicholas G.

1986 Bushman Birth Spacing: A Test for Optimal Interbirth Intervals. Ethology and Sociobiology 7:91-105.

Blurton Jones, Nicholas G., Lars C. Smith, James F. O'Connell, Kristen Hawkes, and C. L. Kamuzora

1992 Demography of the Hadza: An Increasing and High Density Population of Savannah Foragers. American Journal of Physical Anthropology 89:159-181.

Boone, James L.

1998 The Evolution of Magnanimity: When Is it Better to Give than to Receive? Human Nature 9:1-21.

Borgerhoff Mulder, Monique

1988 Reproductive Success in Three Kipsigis Cohorts. In Reproductive Success, T. H. Clutton-Brock, ed. Pp. 419-435. Chicago: University of Chicago Press.

1998 The Demographic Transition: Are We Any Closer to an Evolutionary Explanation? Trends in Ecology and Evolution 13:266-270.

Bowles, Samuel, J. K. Choi, and A. Hopfensitz

2003 The Coevolution of Individual Behaviors and Social Institutions. Journal of Theoretical Biology 223:135-147.

Boyd, Robert, and Peter J. Richerson

1988 The Evolution of Reciprocity in Sizable Groups. Journal of Theoretical Biology 132:337-356.

1989 The Evolution of Indirect Reciprocity. Social Networks 11:213-236.

Clements, K. C., and D. W. Stephens

1995 Testing Models of Nonkin Cooperation: Mutualism and the Prisoner's Dilemma. Animal Behaviour 50:527-535.

Cronk, Lee

1991 Wealth, Status, and Reproductive Success among the Mukogodo of Kenya. American Anthropologist 93:345-360

Dugatkin, Lee Alan

1997 Cooperation among Animals: An Evolutionary Perspective. New York: Oxford University Press. 
Flinn, Mark V.

1986 Correlates of Reproductive Success in a Caribbean Village. Human Ecology 8:225-243.

Gintis, Herbert, Eric Alden Smith, and Samuel L. Bowles

2001 Cooperation and Costly Signaling. Journal of Theoretical Biology 213:103119.

Gurven, Michael

2004 To Give and To Give Not: The Behavioral Ecology of Human Food Transfers. Behavioral and Brain Sciences 27(4). (in press)

Gurven, Michael, et al.

2000a "It's a Wonderful Life": Signaling Generosity among the Ache of Paraguay. Evolution and Human Behavior 21:263-282.

2000b Food Transfers among Hiwi Foragers of Venezuela: Tests of Reciprocity. Human Ecology 28:171-218.

2001 Reservation Food Sharing among the Ache of Paraguay. Human Nature 12:273-297.

Gurven, Michael, Kim Hill, and Hillard Kaplan

2002 From Forest to Reservation: Transitions in Food Sharing Behavior among the Ache of Paraguay. Journal of Anthropological Research 58:91-118.

Hames, Raymond B.

2000 Reciprocal Altruism in Yanomamö Food Exchange. In Adaptation and Human Behavior: An Anthropological Perspective, Lee Cronk, Napoleon Chagnon, and William Irons, eds. Pp. 397-416. Hawthorne, New York: Aldine de Gruyter.

Hawkes, Kristen

1990 Why Do Men Hunt? Some Benefits for Risky Strategies. In Risk and Uncertainty, E. Cashdan, ed. Pp. 145-166. Boulder: Westview Press.

1993a Why HunterGatherers Work. Current Anthropology 34:341-362.

1993b Reply to Hill and Kaplan. Current Anthropology 34:706-710.

Hawkes, Kristen, and Rebecca Bliege Bird

2002 Showing Off, Handicap Signaling, and the Evolution of Men's Work. Evolutionary Anthropology 11:58-67.

Hawkes, Kristen, James F. O'Connell, and Nicholas G. Blurton Jones

1997 Hadza Women's Time Allocation, Offspring Provisioning, and the Evolution of Long Postmenopausal Life Spans. Current Anthropology 38:551-577.

2001a Hadza Meat Sharing. Evolution and Human Behavior 22:113-142.

2001b Hunting and Nuclear Families: Some Lessons from the Hadza about Men's Work. Current Anthropology 42:681-709.

Henrich, Joseph, and Francisco J. Gil-White

2001 The Evolution of Prestige: Freely Conferred Deference as a Mechanism for Enhancing the Benefits of Cultural Transmission. Evolution and Human Behavior 22:165-196.

Hill, Kim, and A. Magdalena Hurtado

1996 Ache Life History: The Ecology and Demography of a Foraging People. Hawthorne, New York: Aldine de Gruyter.

Howell, Nancy W.

1979 Demography of the Dobe !Kung. New York: Academic Press.

Hughes, Austin L.

1986 Reproductive Success and Occupational Class in Eighteenth Century Lancashire, England. Social Biology 33:109-115. 
Irons, William

1979 Cultural and Biological Success. In Evolutionary Biology and Human Social Behavior: An Evolutionary Perspective, Napoleon Chagnon and William Irons, eds. Pp. 257-272. North Scituate, Massachusetts: Duxbury.

Kaplan, Hillard, and Kim Hill

1985a Hunting Ability and Reproductive Success among Male Ache Foragers: Preliminary Results. Current Anthropology 26:131-133.

1985b Food Sharing among Ache Foragers: Tests of Explanatory Hypotheses. Current Anthropology 26:223-246.

Kaplan, Hillard S., Jane B. Lancaster, John A. Bock, and Sara E. Johnson

1995 Does Observed Fertility Maximize Fitness among New Mexican Men? Human Nature 6:325-360.

Kelly, Robert L.

1995 The Foraging Spectrum: Diversity in HunterGatherer Lifeways. Washington, D.C.: Smithsonian Institution Press.

Lessells, Catherine

1991 The Evolution of Life Histories. In Behavioural Ecology: An Evolutionary Approach, third ed., J. R. Krebs and N. B. Davies, eds. Pp. 23-63. Oxford: Blackwell.

Lee, Richard B.

1979 The !Kung San: Men, Women and Work in a Foraging Society. Cambridge and New York: Cambridge University Press.

Low, Bobbi S.

2000 Sex, Wealth, and Fertility: Old Rules, New Environments. In Adaptation and Human Behavior: An Anthropological Perspective, Lee Cronk, Napoleon Chagnon, and William Irons, eds. Pp. 323-344. Hawthorne, New York: Aldine de Gruyter.

Low, Bobbi S., and Alice L. Clarke

1991 Family Patterns in Nineteenth Century Sweden: Impact of Occupational Status and Landownership. Journal of Family History 16:117-138.

Marlowe, Frank

1999 Showoffs or Providers? The Parenting Effort of Hadza Men. Evolution and Human Behavior 20:391-404.

2000 The Patriarch Hypothesis: An Alternative Explanation of Menopause. $\mathrm{Hu}$ man Nature 11:27-42.

2003 A Critical Period for Provisioning by Hadza Men: Implications for Pair Bonding. Evolution and Human Behavior 24:217-229.

Milinski, Manfred, Dirk Semmann, and Hans-Jürgen Krambeck

2002 Donors to Charity Gain in Both Indirect Reciprocity and Political Reputation. Proceedings of the Royal Society of London, Series B 269:881-883.

Mitani, John C., and David P. Watts

2001 Why Do Chimpanzees Hunt and Share Meat? Animal Behaviour 51:915924.

Mohtashemi, M., and L. Mui

2003 Evolution of Indirect Reciprocity by Social Information: The Role of Trust and Reputation in Evolution of Altruism. Journal of Theoretical Biology 223:523531.

Neiman, Fraser D

1998 Conspicuous Consumption as Wasteful Advertising: A Darwinian Perspective on Spatial Patterns in Classic Maya Terminal Monument Dates. In Rediscovering Darwin: Evolutionary Theory and Archeological Explanation, C. Michael 
Barton and Geoffrey A. Clark, eds. Pp. 267-290. Archeological Papers of the American Anthropological Association, No. 7. Washington, D.C.

Panchanathan, Karnik, and Rob Boyd

2004 Indirect Reciprocity Can Stabilize Cooperation without the Second-Order Free Rider Problem. Nature 432:499-502.

Patton, John Q.

2004 Coalitional Effects on Reciprocal Fairness in the Ultimatum Game: A Case from the Ecuadorian Amazon. In Foundations of Human Sociality: Economic Experiments and Ethnographic Evidence from Fifteen Small-scale Societies, Joseph Henrich, Robert Boyd, Samuel Bowles, Colin Camerer, Ernst Fehr, and Herbert Gintis, eds. Pp. 96-124. Oxford: Oxford University Press.

2005 Meat Sharing for Coalitional Support. Evolution and Human Behavior 26, in press.

Ruyle, Eugene E.

1973 Slavery, Surplus, and Stratification on the Northwest Coast: The Ethnoenergetics of an Incipient Stratification System. Current Anthropology 14:603-631.

Sigmund, Karl, Ernst Fehr, and Martin A. Nowak

2002 The Economics of Fair Play. Scientific American 286(1):82-87.

Smith, Eric Alden

1993 Comment on "Why Hunter-gatherers Work" by Kristen Hawkes. Current Anthropology 34:356.

1998 Is Tibetan Polyandry Adaptive? Methodological and Metatheoretical Analyses. Human Nature 9:225-261.

Smith, Eric Alden, and Rebecca L. Bliege Bird

2000 Turtle Hunting and Tombstone Opening: Public Generosity as Costly Signaling. Evolution and Human Behavior 21:245-261.

2005 Costly Signaling and Cooperative Behavior. In Moral Sentiments and Material Interests: On the Foundations of Cooperation in Economic Life, H. Gintis et al., eds. Cambridge, Massachusetts: MIT Press, in press.

Smith, Eric Alden, Rebecca Bliege Bird, and Douglas W. Bird

2003 The Benefits of Costly Signaling: Meriam Turtle-hunters. Behavioral Ecology 14:116-126.

Smith, Eric Alden, Monique Borgerhoff Mulder, and Kim Hill

2001 Controversies in the Evolutionary Social Sciences: A Guide for the Perplexed. Trends in Ecology and Evolution 16:128-135.

Sosis, Richard

2000 Costly Signaling and Torch Fishing on Ifaluk Atoll. Evolution and Human Behavior 21:223-244.

Sugiyama, Lawrence, and Richard Chacon

2000 Effects of Illness and Injury on Foraging among the Yora and Shiwiar: Pathology Risk as Adaptive Problem. In Adaptation and Human Behavior: An Anthropological Perspective, Lee Cronk, Napoleon Chagnon, and William Irons, eds. Pp. 371-395. Hawthorne, New York: Aldine de Gruyter.

Symons, Donald

1989 A Critique of Darwinian Anthropology. Ethology and Sociobiology 10:131144

Trivers, Robert L.

1971 The Evolution of Reciprocal Altruism. Quarterly Review of Biology 46:3557. 
Turke, Paul W., and Laura L. Betzig

1985 Those Who Can, Do: Wealth, Status, and Reproductive Success on Ifaluk. Ethology and Sociobiology 6:79-87.

Voland, Eckart

1990 Differential Reproductive Success within the Krummhörn Population (Germany, 18th and 19th Century). Behavioral Ecology and Sociobiology 26:65-72.

Wiessner, Polly

1996 Leveling the Hunter: Constraints on the Status Quest in Foraging Societies. In Food and the Status Quest: An Interdisciplinary Perspective, Polly Wiessner and Wulf Schiefenhövel, eds. Pp. 171-191. Oxford: Berghahn Books.

2002 Hunting, Healing, and Hxaro Exchange: A Long-Term Perspective on !Kung (Ju/'hoansi) Large-Game Hunting. Evolution and Human Behavior 23:407-436. Wilson, David Sloan

1998 Hunting, Sharing, and Multilevel Selection: The Tolerated Theft Model Revisited. Current Anthropology 39:73-97.

Winterhalder, Bruce

1996 Social Foraging and the Behavioral Ecology of Intragroup Resource Transfers. Evolutionary Anthropology 5:46-57.

Wood, Brian, and Kim Hill

2000 A Test of the "Showing off" Hypothesis with Ache Hunters. Current Anthropology 41:124-125.

Zahavi, Amotz

1995 Altruism as Handicap-The Limitations of Kin Selection and Reciprocity. Journal of Avian Biology 26:1-3. 